\title{
Hubungan Stres dengan Gangguan Siklus Menstruasi Mahasiswi Program Studi Kedokteran Fakultas Kedokteran dan Kesehatan Universitas Muhammadiyah Jakarta Angkatan 2019
}

\author{
Hanny Fitriani ${ }^{1}$, Yusri Hapsari ${ }^{2 *}$ \\ 1) Pendidikan Dokter Umum, Program Studi Kedokteran, Fakultas Kedokteran dan Kesehatan, Universitas Muhammadiyah \\ Jakarta, Indonesia \\ 2) Departemen Psikiatri, Program Studi Kedokteran, Fakultas Kedokteran dan Kesehatan, Universitas Muhammadiyah Jakarta, \\ Indonesia \\ *Corresponding author: hapsarigendhis@gmail.com
}

\begin{abstract}
Background: Menstruation is a natural phenomenon occurring more or less regularly every month during the female reproductive period. Stress is one of the causes of disrupted menstrual cycles. Stress stimulates the Hypothalamus-Pituitary-Adrenal Cortex axis to produce cortisol. The cortisol hormone can interfere with hormonal balance, including reproductive hormones, which affects the menstrual cycle. Purposes: the purpose of this study was to determine the relationship between stress levels and menstrual cycle patterns. Methods: Research design with cross-sectional study approach. The population in this research are all women students of faculty medicine year 2019. The sampling technique uses a total sampling method with a total sample of 110 people. Stress level data is primary data obtained through questionnaire DASS 42, and menstrual cycle data is secondary data from the menstrual cycle questionnaire. Results: Based on the results of this study, statistics found as many as 61 people (55.5\%) deal with stress, and 49 people (44.5\%) do not stress. With bivariate analysis using the Chi-Square test, there was no significant relationship between stress and the menstrual cycle of the 2019 Muhammadiyah University of Jakarta Faculty of Medicine and Health Study Program with a p-value of 0.717 (> 0.05). Conclusion: There is no significant relationship between stress and the menstrual cycle of female students in the Medical Study Program Faculty of Medicine and Health, University of Muhammadiyah Jakarta class of 2019.
\end{abstract}

Keywords: women student of faculty of medicine, menstrual cycle, stress

\begin{abstract}
ABSTRAK
Latar Belakang: Menstruasi adalah fenomena alam yang melibatkan keluarnya darah dari rahim melalui vagina, terjadi kurang lebih secara teratur setiap bulan interval selama masa reproduksi wanita. Stres merangsang Hypothalamus-Pitutarty-Adrenal Cortex aksis untuk menghasilkan kortisol. Hormon kortisol dapat mengganggu keseimbangan hormonal termasuk hormone reproduksi sehingga mempengaruhi siklus menstruasi. Tujuan: Penelitian ini bertujuan untuk mengetahui hubungan antara tingkat stres dengan pola siklus menstruasi. Metode: Desain penelitian dengan pendekatan studi cross-sectional. Populasi pada penelitian ini mahasiswi Program Studi Kedokteran Fakultas Kedokteran dan Kesehatan Universitas Muhammadiyah Jakarta angkatan 2019. Teknik pengambilan sampel menggunakan metode total sampling dengan jumlah sampel sebanyak 110 orang. Data tingkat stres merupakan data primer yang
\end{abstract}


diperoleh melalui kuesioner DASS 42 dan data siklus menstruasi merupakan data sekunder dari kuesioner siklus menstruasi. Hasil: Berdasarkan hasil pada penelitian ini secara statistik ditemukan mahasiswi sebanyak 61 orang (55.5\%) mengalami stres dan 49 orang (44.5\%) tidak mengalami stres. Analisis bivariat menggunakan uji chi-square didapatkan tidak terdapat hubungan yang signifikan antara stres dengan siklus menstruasi mahasiswi Program Studi Kedokteran Fakultas Kedokteran dan Kesehatan Universitas Muhammadiyah Jakarta angkatan 2019 dengan p-value 0.717 (>0.05). Simpulan: Didapatkan hasil bahwa tidak terdapat hubungan yang signifikan antara stres dengan siklus menstruasi mahasiswi Program Studi Kedokteran Fakultas Kedokteran dan Kesehatan Universitas Muhammadiyah Jakarta angkatan 2019.

Kata kunci: mahasiswi fakultas kedokteran, siklus menstruasi, stres

\section{PENDAHULUAN}

Menstruasi adalah fenomena alam yang melibatkan keluarnya darah dari rahim melalui vagina, terjadi kurang lebih secara teratur setiap bulan interval selama masa reproduksi wanita (1). Normal menstruasi pertama kali terjadi pada remaja antara usia 11 hingga 14 tahun, dengan jangka 3 hari hingga 7 hari dan panjang siklus normal 24 hingga 35 hari dengan rata-rata kehilangan darah 20-80 ml. Pola siklus menstruasi ini dipengaruhi oleh usia, tingkat stres, obatobatan dan alat kontrasepsi dalam rahim, kehamilan dan gangguan kehamilan, serta kelainan genetic (2). Pada penelitian yang dilakukan 738 siswi di Arab Saudi didapatkan sembilan puluh satu persen dari siswi menderita masalah menstruasi. Berbagai masalah menstruasi yang dilaporkan, dan insiden mereka termasuk menstruasi tidak teratur (27\%), perdarahan abnormal pada vagina $(9,3 \%)$, amenore $(9,2 \%)$, menorrhagia $(3,4 \%)$, dismenore $(89,7 \%)$, dan gejala pramenstruasi $(46,7 \%)$. Stres tinggi diidentifikasi pada (39\%) siswi. Korelasi positif yang signifikan ditemukan antara stres tinggi dan masalah menstruasi. Siswi dengan stres tinggi memiliki 4 kali, 2 kali, dan 2,8 kali peningkatan resiko untuk mengalami amenore, dismenore, dan sindrom pramenstruasi $(\mathrm{p}<0,05)(2)$.
Stres merupakan suatu respon fisiologis, psikologis dan perilaku manusia untuk beradaptasi dan mengatur baik tekanan internal dan eksternal (stresor). Stres merangsang aksis hypothalamuspituitary-adrenal cortex (HPA), sehingga dihasilkan hormon kortisol menyebabkan terjadinya ketidakseimbangan hormonal termasuk hormon reproduksi dan terjadi suatu keadaan siklus menstruasi yang tidak teratur (2). Berdasarkan hasil penelitian Nasution (2010) yang dilakukan pada mahasiswi Fakultas Kedokteran Universitas Sumatera Utara angkatan 2007, menunjukkan $79,1 \%$ responden dengan stres didapati $23,7 \%$ responden mengalami siklus menstruasi yang tidak teratur. Sebanyak 20,9\% yang tidak stres didapati $0,7 \%$ mengalami siklus menstruasi yang tidak teratur. Data beberapa hasil studi juga dikatakan bahwa wanita yang menderita stres dilaporkan sebanyak 22,1\% mengalami menstruasi tidak teratur $(3,4)$.

Berdasarkan Penelitian dari Khairunisa (2017) yang dilakukan pada Mahasiswi Prodi Kedokteran Fakultas Kedokteran dan Kesehatan Universitas Muhammadiyah Jakarta angkatan 20152017, ditemukan responden pada angkatan 2015 dengan total responden 60 orang ditemukan yang mengalami stres ringan 
dengan derajat nyeri ringan 15 orang, stres ringan dengan derajat nyeri sedang dan berat 16 orang, stres sedang dan stres berat dengan derajat nyeri ringan 3 orang, stres sedang dan stres berat dengan derajat nyeri sedang dan berat 26 orang. Pada angkatan 2016 dengan jumlah 60 responden ditemukan stres ringan dengan derajat nyeri ringan 14 orang, stres ringan dengan derajat nyeri sedang dan berat 15 orang, stres sedang dan stres berat dengan derajat nyeri ringan 4 orang, stres sedang dan stres berat dengan derajat nyeri sedang dan berat 27 orang. Sedangkan pada angkatan 2017 ditemukan stres ringan dengan derajat nyeri ringan 17 orang, stres ringan dengan derajat nyeri sedang dan berat 4 orang, stres sedang dan stres berat dengan derajat nyeri ringan 4 orang, stres sedang dan stres berat dengan derajat nyeri sedang dan berat 35 orang. Saat dilakukan uji statistik didapatkan $p$ value $<0.05$ yang berarti terdapat hubungan yang signifikan antara stres dengan sindrom dismenore (5).

Berdasarkan pernyataan di atas, peneliti tertarik untuk melakukan penelitian mengenai Hubungan Antara Tingkat Stres Dengan Pola Siklus Menstruasi Mahasiswi Program Studi Kedokteran Fakultas Kedokteran dan Kesehatan Universitas Muhammadiyah Jakarta angkatan 2019. Peneliti memilih tempat ini sebagai lokasi penelitian dikarenakan belum pernah dilakukan penelitian terkait kejadian antara tingkat stress dengan siklus menstruasi.

\section{METODE}

Dalam penelitian ini menggunakan pendekatan desain cross-sectional, menggunakan data primer yaitu menggunakan kuesioner yang di ambil langsung ke responden, dengan rancangan penelitian deskriptif. Penelitian ini dilaksanakan di Program Studi Kedokteran Fakultas Kedokteran dan Kesehatan Universitas Muhammadiyah Jakarta pada bulan Februari - Mei 2020. Sampel yang diambil dalam penelitian ini adalah seluruh mahasiswi Program Studi Kedokteran Fakultas Kedokteran dan Kesehatan Universitas Muhammadiyah Jakarta Angkatan 2019. Teknik yang digunakan adalah total sampling dengan total 110 mahasiswi.

Variabel penelitian terdiri dari variabel independen yaitu stres dan variabel dependen yaitu pola siklus menstruasi. Stres diukur dengan kuesioner Depression Anxiety Stress Scale 42 (DASS 42), penelitian ini memilih kuesioner yang mengukur tentang stres yaitu sejumlah 14 pertanyaan menggunakan standar yang telah ditentukan oleh DASS 42 dibagi menjadi dua golongan yaitu:

1. Skor normal $(\leq 14)$

2. Skor stres $(>14)$

Siklus menstruasi menggunakan kuesioner menstruasi, yang di golongkan menjadi tiga seperti di bawah ini: (6)

1. Siklus menstruasi normal $(24-35$ hari)

2. Oligomenorea (lebih dari 35 hari)

3. Polimenorea (kurang dari 24 hari)

Analisis penelitian ini menggunakan analisis univariat untuk mengetahui distribusi frekuensi, sedangkan analisis bivariate menggunakan Pearson Chisquare dengan taraf $\alpha 0,05$. Apabila $\alpha<$ 0,05 maka terdapat hubungan yang signifikan antara kedua variabel.

\section{HASIL}

Penelitian yang dilakukan dari Februari Mei 2020 pada mahasiswi Program Studi Kedokteran Fakultas Kedokteran dan Kesehatan Universitas Muhammadiyah Jakarta dengan 110 mahasiswi. Setelah 
dilakukan penyebaran kuesioner terkumpul 110 kuesioner.

Tabel 1. Karakteristik Mahasiswi Program Studi Kedokteran Fakultas Kedokteran dan Kesehatan Universitas Muhammadiyah Jakarta

\begin{tabular}{lcc}
\hline Variabel & $\begin{array}{c}\text { Frekuensi } \\
(\mathbf{N})\end{array}$ & $\begin{array}{c}\text { Persentase } \\
(\boldsymbol{\%})\end{array}$ \\
\hline Umur & & \\
18 & 14 & 12,7 \\
19 & 63 & 27,3 \\
20 & 29 & 26,4 \\
21 & 1 & 0,9 \\
22 & 2 & 1,8 \\
26 & 1 & 0,9 \\
Total & 110 & 100 \\
\hline
\end{tabular}

Berdasarkan data pada Tabel 1 dapat diartikan sebanyak 14 responden $(12,7 \%)$ dengan umur 18 tahun, 63 responden $(63 \%)$ dengan umur 19 tahun, 29 reponden $(26,4 \%)$ dengan umur 20 tahun, 1 responden $(0,9 \%)$ dengan umur 21 tahun, 2 reponden $(1,8 \%)$ dengan umur 22 tahun, dan 1 responden $(0,9 \%)$ dengan usia 26 tahun. Dapat diketahui umur 19 tahun memberikan kontribusi terbanyak terhadap penelitian ini.

Tabel 2. Gambaran Stres pada Mahasiswi Program Studi Kedokteran Fakultas Kedokteran dan Kesehatan Universitas Muhammadiyah Jakarta

\begin{tabular}{lcc}
\hline Variabel Stres & $\begin{array}{c}\text { Frekuensi } \\
(\mathbf{N})\end{array}$ & $\begin{array}{c}\text { Persentase } \\
(\mathbf{\%})\end{array}$ \\
\hline Stres & 61 & 55,5 \\
Tidak Stres & 49 & 44,5 \\
Total & 110 & 100 \\
\hline
\end{tabular}

Pada Tabel 2 didapatkan bahwa mahasiswi yang mengalami stress sebanyak $55,5 \%$ dan yang tidak stress sebanyak 44,5\%. Berdasarkan tabel 3 dapat diketahui pada mahasiswi di Prodi Kedokteran Fakultas
Kedokteran dan Kesehatan Universitas Muhammadiyah Jakarta pada angkatan 2019 dominan mengalami siklus menstruasi yang normal yaitu sebanyak 63 orang $(57,3 \%)$.

Tabel 3. Siklus Menstruasi Mahasiswi Prodi Kedokteran Fakultas Kedokteran dan Kesehatan Universitas Muhammadiyah Jakarta

\begin{tabular}{lcc}
\hline \multicolumn{1}{c}{$\begin{array}{c}\text { Siklus } \\
\text { Menstruasi }\end{array}$} & $\begin{array}{c}\text { Frekuensi } \\
(\mathbf{N})\end{array}$ & $\begin{array}{c}\text { Persentase } \\
(\boldsymbol{\%})\end{array}$ \\
\hline Siklus & 63 & 57,3 \\
menstruasi & & \\
normal & & \\
Siklus menstruasi & terganggu & \\
Oligomenorea & 27 & 24,5 \\
Polimenorea & 20 & 18,2 \\
Total & 110 & 100 \\
\hline
\end{tabular}

Tabel 4. Hubungan Stres dengan Gangguan Siklus Menstruasi Mahasiswi Program Studi Kedokteran Fakultas Kedokteran dan Kesehatan Universitas Muhammadiyah Jakarta Angkatan 2019

\begin{tabular}{|c|c|c|c|c|c|c|}
\hline & \multicolumn{2}{|c|}{$\begin{array}{l}\text { Tidak } \\
\text { Stres }\end{array}$} & \multicolumn{2}{|c|}{ Stres } & \multirow{2}{*}{$\begin{array}{c}\text { OR } \\
(95 \% \\
\text { CI })\end{array}$} & \multirow{2}{*}{$\begin{array}{c}\text { Nilai } \\
\mathbf{p}\end{array}$} \\
\hline & $\mathbf{N}$ & $\%$ & $\mathbf{N}$ & $\%$ & & \\
\hline Siklus & & & & & \multirow{4}{*}{$\begin{array}{c}1.151 \\
(0,538- \\
2,466)\end{array}$} & \multirow{4}{*}{0,717} \\
\hline Menstruasi & 29 & 26 & 34 & 31 & & \\
\hline $\begin{array}{l}\text { Normal } \\
\text { Gangguan }\end{array}$ & & & & & & \\
\hline $\begin{array}{l}\text { Siklus } \\
\text { Menstruasi }\end{array}$ & 20 & 18 & 27 & 25 & & \\
\hline
\end{tabular}

Pada Tabel 4 didapat nilai estimasi risiko untuk odds ratio dimensi stres yaitu sebesar 1,151, yang berarti stres memiliki risiko gangguan siklus menstruasi sebesar 1,15. Nilai signifikansi Pearson Chi-Square dimensi stres 0,717. ( $p$ value $>0,05$ ), maka tidak terdapat hubungan signifikan stres dengan gangguan siklus menstruasi mahasiswi Program Studi Kedokteran Fakultas Kedokteran dan Kesehatan 
Universitas Muhammadiyah Jakarta Angkatan 2019.

\section{PEMBAHASAN}

Pada hasil analisis univariat pada mahasiswi Program Studi Kedokteran Fakultas Kedokteran dan Kesehatan Universitas Muhammadiyah Jakarta Angkatan 2019 dapat diketahui usia 19 tahun memberikan kontribusi terbanyak terhadap penelitian ini. Hal ini tidak sesuai dengan penelitian yang dilakukan oleh Yudita dkk (2017) dalam penelitian yang dilakukan responden paling banyak berusia 20 tahun hingga 22 tahun, dimana usia termasuk dalam masa reproduksi yaitu masa sekitar usia 20-40 tahun. Selama masa reproduksi, secara umum siklus menstruasi teratur normal dan tidak banyak mengalami perubahan $(2,3,6)$.

Berdasarkan hasil univariat, mahasiswi Program Studi Kedokteran Fakultas Kedokteran dan Kesehatan Universitas Muhammadiyah Jakarta Angkatan 2019 mengalami stres sebanyak 61 orang $(55.5 \%)$ dan yang tidak mengalami stres 49 orang $(44.5 \%)$. Data tersebut sesuai dengan penelitian Nasution (2010) yang menunjukkan $79.1 \%$ responden dengan stres pada penelitian ini yaitu 61 orang $(55.5 \%)$. Menurut Nasution (2010), hal ini dapat terjadi karena tekanan dari dalam dan luar diri dalam proses belajar di fakultas kedokteran (4). Hasil penelitian ini berbeda dengan dengan penelitian yang dilakukan dengan Rafique dan Al-Sheikh (2018) yang dilakukan pada 738 siswi di Arab Saudi didapatkan sembilan $91 \%$ dari siswi menderita masalah menstruasi (1).

Berdasarkan hasil pengujian menggunakan pearson chi-square $p$ value $=0,717 \quad(>0,05)$ (tabel 4) yang memiliki arti tidak ada hubungan bermakna antara stres dengan gangguan siklus menstruasi mahasiswi Program Studi Kedokteran Fakultas Kedokteran dan Kesehatan Universitas Muhammadiyah Jakarta Angkatan 2019. Hal ini dapat terjadi karena stres merupakan salah satu penyebab terganggu siklus menstruasi. Ada faktor risiko yang lain seperti usia, obatobatan, alat kontrasepsi dalam rahim, kehamilan, gangguan kehamilan, serta kelainan genetik (7-9). Penelitian ini menggunakan desain studi cross sectional dan sampel yang diambil sudah sesuai dengan kriteria inklusi dan kriteria eksklusi. Penelitian menggunakan kuesioner DASS (Depression Anxiety Stress Scale) yang berfokus pada stress, dibagi menjadi normal atau tidak stres, stres ringan, stres sedang, stres berat, dan stres sangat berat (7).

Pada siklus menstruasi dikategorikan siklus menstruasi normal, polimenorea, oligomenorea, dan amenorea. Hasil uji statistik tidak terdapat hubungan yang signifikan pada mahasiswi Pendidikan Dokter Fakultas Kedokteran Universitas Andalas angkatan 2011 dikarenakan oleh beberapa faktor yaitu jumlah responden yang kurang. Penelitian cross sectional memerlukan responden yang cukup besar stres bersifat subjektif dan individual (2).

Penelitian serupa ditemukan oleh Yudita dkk (2017) dengan menggunakan sampel sebanyak 110 orang mahasiswi dari Pendidikan Dokter Fakultas Kedokteran Universitas Andalas angkatan 2011 hasilnya menunjukkan bahwa tidak terdapat hubungan yang bermakna antara stres dengan pola siklus menstruasi pada mahasiswi Pendidikan Dokter Fakultas Kedokteran Universitas Andalas angkatan 2011 (2).

Sebaliknya, pada penelitian Rafique et all (2018) dengan menggunakan sampel 
sebanyak 738 mahasiswi dari Universitas kesehatan Immam Abdulrahman bin Faisal, Dammam, Arab Saudi, dengan desain studi cross sectional dengan lama penelitian 1 tahun. Responden sudah memenuhi kriteria inklusi dan eksklusi. Penelitian ini menggunakan PSS (Perceived Stress Scale 10) yang memiliki klasifikasi diantaranya stres yang rendah, stres sedang, stress tinggi. Pada siklus menstruasi dirancang oleh penulis dengan memperhatikan pola menstruasi seperti usia menarche, panjang siklus menstruasi, banyaknya darah yang keluar saat menstruasi, keteraturan menstruasi, riwayat amenorea, disminorea, dan gejala menstruasi (1).

Pada penelitian Hazanah (2017), responden penelitian mahasiswa kebidanan usia 18-21 tahun, tekhnik pengambilan sampel secara stratified random sampling berjumlah 132 orang dan desain studi cross sectional. Responden sudah memenuhi kriteria inklusi dan eksklusi (10). Variabel stres alat ukur yang digunakan adalah PSS (Perceived Stress Scale) yang terdiri dari 10 pertanyaan dan skala yang digunakan yaitu skala likert, sedangkan pada siklus menstruasi peneliti menggunakan angket tertutup. Angket untuk mengukur variabel dependen terdiri dari 3 pertanyaan untuk mengetahui siklus menstruasi tiap bulan dalam tiga bulan terakhir. Responden dengan siklus menstruasi 21-35 dalam 3 bulan berturut-turut berarti mengalami siklus menstruasi teratur dan responden dengan siklus menstruasi $<21$ hari atau > 35 hari atau tidak menstruasi 3 bulan berturut-turut berarti mengalami siklus menstruasi tidak teratur $(6,10)$.

\section{SIMPULAN}

Tidak terdapat hubungan yang signifikan antara stres dengan siklus menstruasi, penyebab gangguan siklus mentruasi mungkin dari penyebab lain seperti usia, obat-obatan, alat kontrasepsi dalam rahim, kehamilan, gangguan kehamilan, serta kelainan genetik.

\section{UCAPAN TERIMA KASIH}

Syukur alhamdulillah dan terima kasih kepada semua yang mendukung penulisan ini.

\section{KONFLIK KEPENTINGAN}

Penulis tidak memiliki konflik kepentingan yang dapat menimbulkan pertanyaan bias dalam diskusi dan kesimpulan naskah.

\section{REFERENSI}

1. Rafique N, Al-Sheikh $\mathrm{MH}$. Prevalence of menstrual problems and their association with psychological stress in young female students studying health sciences. Saudi Med J. 2018;39(1):67-73.

2. Yudita NA, Yanis A, Iryani D. Hubungan antara Stres dengan Pola Siklus Menstruasi Mahasiswi Fakultas Kedokteran Universitas Andalas. J Kesehat Andalas. 2017;6(2):299.

3. Elvira SD, Sukanto GH. Faktor Psikologis Yang Mempengaruhi Kondisi medis. In: Buku Ajar Psikiatri. 2nd ed. Jakarta: Badan Penerbit FKUI; 2013. p. 572-85.

4. Nasution I. Hubungan Stres dengan Siklus Menstruasi yang Tidak Teratur pada Mahasiswa Fakultas Kedokteran USU Angkatan 2007. Universitas Sumatera Utara; 2010.

5. Khairunnisa A. Hubungan Tingkat Stres Dengan Derajat Nyeri Sindrom Disminorea Pada Mahasiswi Program Studi Kedokteran Fakultas Kedokteran dan Kesehatan Universitas Muhammadiyah Jakarta 
Angkatan 2015-2017. Universitas Muhammadiyah Jakarta; 2017.

6. Prawirohardjo S. Ilmu Kandungan. 3rd ed. Anwar M, Baziad A, Prabowo, Prajinto R, editors. Jakarta: PT Bina Pustaka; 2011.

7. Lovibond P. Depression Anxiety Stress Scales (DASS) [Internet]. Psychology Foundation of Australia. 2018 [cited 2020 Mar 1]. Available from:

http://www2.psy.unsw.edu.au/dass//

8. Maramis M. Tatalaksana Gangguan Mental untuk Dokter Layanan Primer. 2nd ed. Surabaya: FK Unair;
2015.

9. Fitri Kumalasari ML, Hadi MI, Munir M. Hubungan Tingkat Stres Psikologis Dengan Siklus Menstruasi Pada Mahasiswa. J Kesehat. 2019;12(2):131.

10. Hazanah S. Hubungan Stress Dengan Siklus Menstruasi pada Usia 18-21 tahun. Husada Mahakam [Internet]. 2014 Jul 9;3(7). Available from:

http://husadamahakam.poltekkeskaltim.ac.id/ojs/index.php/Home/art icle/view?path= 